\title{
Primary percutaneous intervention in anterior wall myocardial infarction with isolated dextrocardia and diaphragmatic hernia
}

\begin{abstract}
Non Structured abstract
Isolated dextrocardia is a very rare congenital anomaly. There are very few case reports on primary percutaneous coronary intervention in acute ST elevation myocardial infarction patients with associated isolated dextrocardia and diaphragmatic hernia. Coronary angiography and percutaneous coronary interventions may sometimes be technically difficult to the experienced interventional cardiologist because of mirror image dextrocardia. We hereby report a 52years old male who presented with acute ST elevation anterior wall myocardial infarction with isolated dextrocardia. He underwent successful primary coronary angioplasty and stenting of a stenosed middle left anterior descending artery.
\end{abstract}

Keywords: primary percutaneous intervention, myocardial infarction, dextrocardia, diaphragmatic hernia

\author{
Volume 8 Issue 5 - 2017 \\ Shankar Laudari,' Sachin Dhungel,' Kaushal \\ K Tiwari, ${ }^{2}$ Subramanyam $\mathrm{G}^{3}$ \\ 'Lecturer, Department of Cardiology, College of Medical \\ Sciences-Teaching Hospital, India \\ ${ }^{2}$ Associate Professor, Department of Cardiology, College of \\ Medical Sciences-Teaching Hospital, India \\ ${ }^{3}$ Professor, Department of Cardiology, College of Medical \\ Sciences-Teaching Hospital, India
}

\begin{abstract}
Correspondence: Shankar Laudari, DM Cardiology, Lecturer, College of Medical Sciences-Teaching Hospital, Bharatpur, Nepal,
\end{abstract} India,Tel 977-9845I I2909, Email ishankar2@hotmail.com

Received: January 02, 2017 | Published: April 19, 2017

\section{Introduction}

Dextrocardia is a rare congenital defect in which the apex of the heart is located on the right side of the thorax. There are two main types of dextrocardia: dextrocardia of embryonic arrest (also known as isolated dextrocardia) and dextrocardia situs inversus. Isolated dextrocardia is commonly associated with severe defects of the heart and related abnormalities including pulmonary hypoplasia. Coronary artery disease (CAD) with dextrocardia is presumed to be of similar frequency as in the general population. The coronary angiography and percutaneous coronary intervention (PCI) in these patients is technically difficult and requires some modification, such as mirror image angiographic angulation, proper catheter selection and catheter manipulation for selective cannulation of the coronaries. We describe a case of dextrocardia and acute myocardial infarction (MI), with successful primary coronary angioplasty and stenting of a culprit middle left anterior descending artery (LAD).

\section{Case summary}

52 years male who is a chronic smoker with systemic hypertension was referred to our center for management of acute ST elevation anterior wall MI. He was managed in outside cardiac center with thrombolysis with streptokinase. Patient gives the past history of thoracotomy for repair of diaphragmatic hernia. On clinical examination, vitals were stable. Cardiovascular system (CVS) examination: Apex localized to the right 5 th intercostal space. There was decreased air entry over the left inter/infrascapular and axillary lung zones. Chest X-ray was suggestive of elevation of left dome of diaphragm with fundus air shadow with dextrocardia (apex pointed to right side with right sided aortic knuckle) (Figure 1). Electrocardiogram was suggestive of dextrocardia (decreasing voltages from V1-V6) as shown below in Figure 2. Echocardiography showed dextrocardia with mild LV systolic dysfunction (LVEF-40\%) with regional wall motion abnormality (RWMA) along LAD territory. Troponin I was positive $(0.1 \mathrm{ng} / \mathrm{ml})$ and CPK-MB was $80 \mathrm{IU} / \mathrm{L}$. Coronary angiography was done with Judkins left and right (JL and JR) $3.5 \times 6 \mathrm{~F}$ diagnostic catheter. It revealed single vessel disease over mid-LAD $(90 \%$ stenosis) as shown in Figure 3. Subsequently, left coronary artery was hooked with EBU $3.5 \times 6 \mathrm{~F}$ catheter. BMW wire was used to cross the lesion followed by multiple predilatations with $2 \times 10 \mathrm{~mm}$ balloon. Successful PCI was done with deployment of NOVUS drug eluting stent (Sirolimus eluting stent) $2.75 \times 32 \mathrm{~mm}$ at $14 \mathrm{~atm}$.pressure as illustrated in Figure 4. $150 \mathrm{ml}$ of contrast (non-ionic, iso-osmolar Iohexol) was used during the procedure. TIMI III flow was achieved. During shifting of the patient to the coronary care unit (CCU), patient had accelerated hypertension with increasing shortness of breath and desaturation $(\mathrm{Sp} 02<90 \%)$ which was suggestive of acute pulmonary edema. The patient responded with diuretics, nitroglycerin infusion, morphine and high flow oxygen support within hours. Patient was discharged on fourth day in stable condition.

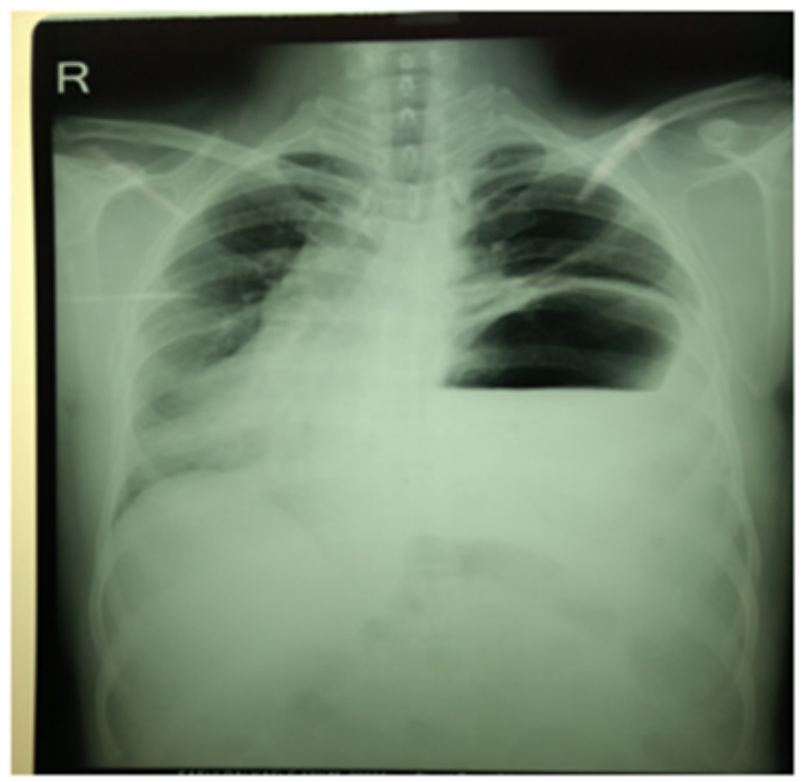

Figure I Chest X-ray of an anterior wall MI patient with isolated dextrocardia with left dome of diaphragm elevation following thoracotomy. 


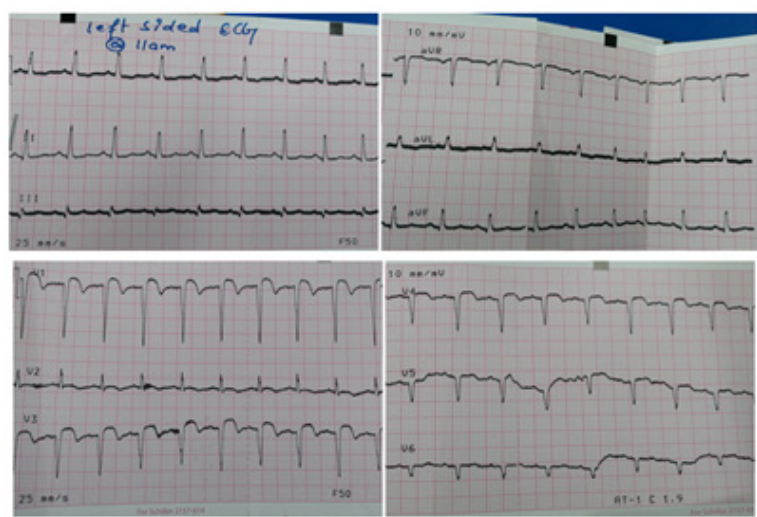

Figure 2 ECG findings of Anterior wall MI with isolated dextrocardia.

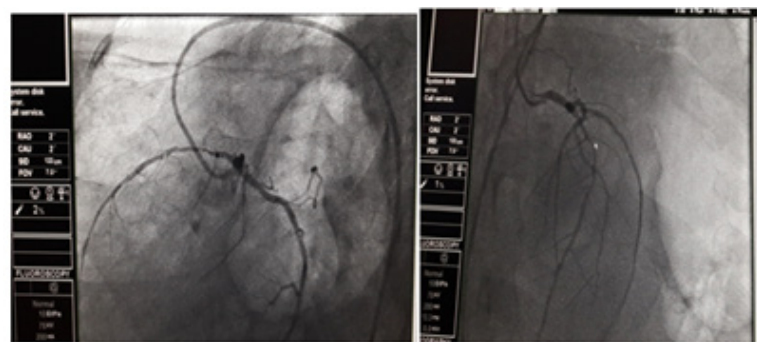

Figure 3 Coronary angiography shows mid-LAD 95\% stenosis.

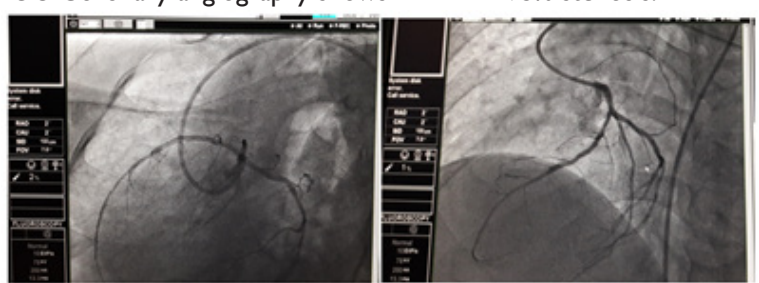

Figure 4 Coronary angioplasty of mid-LAD with deployment of NOVUS (SES) $2.75 \times 32 \mathrm{~mm}$ stent.

\section{Discussion}

Dextrocardia is a rare congenital cardiac anomaly with a prevalence of 1 in 10,000 births..$^{1,2}$ In the absence of other structural heart disease, the life expectancy is usually normal. The association of $\mathrm{CAD}$ in these patients is the same as in the general population. Hence, even elderly patients with this rare anomaly have been subjected to successful percutaneous or surgical intervention of CAD, as reported in the literature. ${ }^{3,4}$ The selective cannulation of the coronary arteries might be difficult because of mirror images, for which the operator is not accustomed and also one has to rotate the catheter anticlockwise in the aorta, instead of the routine clockwise rotation for cannulation of the RCA. It is also difficult to find an appropriate angiographic view to visualize the lesion, which subsequently may also lead to a greater amount of contrast use. In our case, the coronary arteries cannulation was easy both for a diagnostic angiogram and for PCI. Sometimes, it may be technicaly difficult because of different spatial positions of the RCA and left main ostium, for which one is not accustomed in routine catheterization practice. A double-inversion technique of Goel, ${ }^{5}$ in which all angiographic pictures are normalized to the standard conventional pictures, as seen in a normally located heart by doing a combination of a right-left reversal of the image on the monitor using the "horizontal sweep reverse" function during acquisition and a reversed RAO/LAO angle selection, can help in better localization and delineation of the coronary anatomy. ${ }^{6}$ In our case, we used BMW wire to cross the lesion followed by multiple predilatations with $2 \times 10 \mathrm{~mm}$ balloon followed by DES deployment. We could perform the successful PCI without the use of the "double reverse technique". Thus, we report a rare case of acute ST elevation anterior wall myocardial infarction in a patient with isolated dextrocardia, with successful emergency primary coronary angioplasty and drug eluting stenting of a mid-LAD.

\section{Conclusion}

Coronary angiography and Primary PCI in a patient with acute ST elevation myocardial infarction with isolated dextrocardia with associated diaphragmatic hernia may sometimes be technically challenging even to the experienced coronary interventionists. However, the procedure was easy and uneventful in our case.

\section{Acknowledgments}

I would like to specially thank Dr Ruchi Mittal, Mr Indra Prasad Dumre and the entire cath. lab. team for their immense help and cooperation.

\section{Conflicts of interest}

Author declares there are no conflicts of interest.

\section{Funding}

None.

\section{References}

1. Rosenberg HN, Rosenberg IN. Simultaneous association of situs inversus, coronary heart disease and hiatus hernia; report of a case and review of literature. Ann Intern Med. 1949; 30(4):851-859.

2. Evans WN, Acherman RJ, Collazos JC, et al. Dextrocardia: practical clinical points and comments on terminology. Pediatr Cardiol. 2010;31(1):1-6.

3. Bonde P, Campalani GF. Myocardial revascularization for situs inversus totalis and dextrocardia. Interact Cardiovasc Thorac Surg. 2003;2(4):486-488.

4. Saadi EK, Dussin LH, Nicolao A, et al. Coronary artery bypass grafting in a patient with situs inversus totalis and dextrocardia. Rev Bras Cir Cardiovasc. 2007;22(3):346-348.

5. Goel PK. Double-inversion technique for coronary angiography viewing in dextrocardia. Catheter Cardiovasc Interv. 2005;66(2):281-285.

6. Robinson N, Golledge P, Timmis A. Coronary stent deployment in situs inversus. Heart. 2001;86(5):E15. 